\title{
Inhibition of glucose-6-phosphate dehydrogenase sensitizes cisplatin-resistant cells to death
}

\author{
Daniela Catanzaro ${ }^{1}$, Edoardo Gaude ${ }^{2}$, Genny Orso $^{3}$, Carla Giordano ${ }^{4}$, Giulia Guzzo ${ }^{5}$, \\ Andrea Rasola ${ }^{5}$, Eugenio Ragazzi ${ }^{1}$, Laura Caparrotta ${ }^{1}$, Christian Frezza ${ }^{2}$, \\ Monica Montopoli ${ }^{1}$ \\ ${ }^{1}$ Department of Pharmaceutical and Pharmacological Sciences, University of Padova, Padova, Italy \\ ${ }^{2}$ MRC Cancer Unit, University of Cambridge, Hutchison/MRC Research Centre, Cambridge Biomedical Campus, \\ Cambridge, UK \\ ${ }^{3}$ IRCCS "E. Medea", Conegliano, Italy \\ ${ }^{4}$ Department of Radiological, Oncological and Pathological Sciences, Sapienza University of Rome, Roma, Italy \\ ${ }^{5}$ Department of Biomedical Sciences, University of Padova, Padova, Italy
}

Correspondence to:

Christian Frezza, e-mail: cf366@mrc-cu.cam.ac.uk

Monica Montopoli, e-mail: monica.montopoli@unipd.it

Keywords: cisplatin, drug resistance, cancer metabolism, PPP, transmitochondrial hybrids

Received: March 22, $2015 \quad$ Accepted: August 07, $2015 \quad$ Published: August 17, 2015

\section{ABSTRACT}

The mechanisms of cisplatin resistance, one of the major limitations of current chemotherapy, has only partially been described. We previously demonstrated that cisplatin-resistant ovarian cancer cells (C13), are characterized by reduced mitochondrial activity and higher glucose-dependency when compared to the cisplatinsensitive counterpart (2008). In this work we further characterized the role of metabolic transformation in cisplatin resistance. By using transmitochondrial hybrids we show that metabolic reprogramming of cisplatin-resistant cell is not caused by inherent mtDNA mutations. We also found that $\mathrm{C} 13$ cells not only present an increased glucose-uptake and consumption, but also exhibit increased expression and enzymatic activity of the Pentose Phosphate pathway (PPP) enzyme Glucose-6-Phosphate Dehydrogenase (G6PDH). Moreover, we show that cisplatin-resistant cells are more sensitive to G6PDH inhibition. Even if the metabolomic fingerprint of ovarian cancer cells remains to be further elucidated, these findings indicate that PPP offers innovative potential targets to overcome cisplatin resistance.

\section{INTRODUCTION}

Cisplatin is one of the most potent anticancer agents used in the treatment of various solid tumors including testicular, lung and ovarian cancer [1]. Despite the chemotherapeutic advances of the last decades, cisplatin still remains the first-line chemotherapeutic agent against epithelial malignancies, used alone or in combination with radiotherapy and/or other anticancer compounds. Cisplatin has been shown to induce the formation of inter- and intra-strand nuclear DNA (nDNA) cross-links that, by hindering both RNA transcription and DNA replication, lead to cell cycle arrest and apoptosis [2]. Cisplatin has also been shown to bind to mitochondrial DNA (mtDNA), which, unlike nDNA, is more susceptible to the onset of mutations that lead to mitochondrial dysfunction, oxidative stress and mitochondria-dependent apoptosis $[3,4,5]$. The cisplatin therapeutic effectiveness is limited by side effects (ototoxicity, nephrotoxicity and neurotoxicity) [6] and by the emergence of resistance [7], a multi-factorial phenomenon, linked to reduced drug accumulation, inactivation by thiol-containing species, increased repair of platinum-DNA adducts, enhanced tolerance to cisplatin adducts and desensitization to cell death pathways $[8,9,10]$. These mechanisms are cell linedependent, so that a particular tumor may exhibit one, two or even all the above-mentioned mechanisms [11].

In our previous studies we demonstrated that cisplatin-resistant ovarian cancer cells exhibit lower levels of Reactive Oxygen Species (ROS) and increased steady 
state levels of reduced glutathione (GSH) [12] suggesting that cisplatin-resistance can also be associated with the variation of intracellular redox status. It is well established that GSH plays a key role in the antioxidant capabilities of cancer cells, but it is important to remember that GSH also acts forming complexes with cisplatin, thereby reducing the amount of intracellular drug available for interaction with all nucleophilic sites [13].

Cancer cells undergo profound metabolic changes required to fuel the biosynthetic demands of cell growth and division $[14,15]$ and to maintain the redox homeostasis. This metabolic rewiring is orchestrated by oncogenes and tumor suppressors, which fine tune several metabolic pathways, including glycolysis, oxidative phosphorylation, the pentose phosphate pathway and glutaminolysis [16]. Indeed, the increase in glucose metabolism, that hallmarks most cancer cells, is instrumental not only for ATP generation or for the synthesis of nucleotides and amino acids, but also for the maintenance of redox homeostasis via the NADPHproducing Pentose Phosphate Pathway (PPP) [17]. The rate-limiting and "gatekeeper" enzyme of the PPP is glucose-6-phosphate dehydrogenase (G6PDH), whose activity is regulated by the availability of its substrate and by the NADP+/NADPH ratio [18] and directly reflects the partitioning of glucose utilization between glycolysis and oxidative PPP [19]. However, whether the metabolic reprogramming of cancer supports cisplatin resistance is currently unknown.

To shed some light on the metabolic determinants of cisplatin resistance, we had investigated the metabolic changes that occur in cisplatin-resistant ovarian cancer cells (C13), finding that they exhibit reduced oxygen consumption and increased dependency on glucose, when compared to their cisplatin-sensitive counterpart (2008) [20]. In this work we have further characterized the role of metabolic transformation in cisplatin resistance. We show that cisplatin induces deregulation of mitochondrial function in resistant cells, in accord with their increased usage of glucose, and that cisplatin-resistant cells rely on the PPP to overcome cisplatin cytotoxicity. We also demonstrate that the inhibition of the limiting enzyme of the PPP, G6PDH, restores cisplatin sensitivity in cisplatinresistant cells.

\section{RESULTS}

\section{Role of mtDNA polymorphisms in cisplatin resistance}

We initially investigated whether the mitochondrial dysfunction observed in cisplatin-resistant cells is a consequence of the damaging effects of cisplatin on mtDNA. To this aim, the mtDNA of C13 cells and of their cisplatin-sensitive counterpart 2008, was sequenced (Table 1). These analyses revealed three major polymorphisms in $\mathrm{C} 13$ cells: $8156 \mathrm{G}>\mathrm{T}, 12018 \mathrm{C}>\mathrm{T}$, $13828 \mathrm{C}>\mathrm{T}$. Their putative pathogenicity was assessed by PolyPhen (http://genetics.bwh.harvard.edu/pph2/), a software application that predicts the impact of an amino acid substitution on the structure and function of a protein. The predicted pathogenicity of the $8156 \mathrm{G}>\mathrm{T}$ and $13828 \mathrm{C}>\mathrm{T}$ polymorphisms was modest, whereas the $12018 \mathrm{C}>\mathrm{T}$ polymorphism resulted mildly pathogenic. In order to investigate if these mtDNA polymorphisms contributed to the altered mitochondrial function and cisplatin resistance, we generated trans-mitochondrial cytoplasmic hybrids (cybrids) (Supplementary Figure 1A for a schematic representation of the experiment). Interestingly, the cybrid lines (H2008 and HC13) were equally sensitive to cisplatin, as demonstrated by trypan blue exclusion assay and by Annexin $\mathrm{V}$ assay (Supplementary Figure 1B-1C). In line with our previous observations, cisplatin-resistant $\mathrm{C} 13$ cells presented lower oxygen consumption (Figure 1A) and lower mitochondrial potential (Figure 1B) when compared to 2008 cells. Interestingly, both respiration and mitochondrial potential defects were restored in the cybrid cell line $\mathrm{HC} 13$ and were comparable to the original 2008 cells (Figure 1A-1B). We further assessed the presence of mitochondrial dysfunction in $\mathrm{C} 13$ cells and in cybrid cell lines by growing cells in galactose medium. Of note, $\mathrm{C} 13$ cells were extremely sensitive to these culture conditions (Figure 1C), whereas their viability was not affected by long-term incubation with the Complex I inhibitor rotenone (Figure 1D). In further support of the restoration of mitochondrial function in cybrids, growth of $\mathrm{HC} 13$ cells was not affected by galactose, and $\mathrm{HC} 13$ cells became sensitive to rotenone (Figure 1C-1D). Together, these results suggest that the mitochondrial polymorphisms found in $\mathrm{C} 13$ cells do not directly contribute to the observed mitochondrial dysfunction and do not play a role in cisplatin resistance.

\section{Cisplatin-resistant cells exhibit defects in mitochondrial morphology and a reduction in mitochondrial mass}

We wanted to investigate whether decreased oxygen consumption observed in $\mathrm{C} 13$ cells was caused by a decrease in mitochondrial mass. To this aim, cells were stained with mitotracker green (MTG), a potentialindependent mitochondrial probe, and mitochondrial mass was analysed using confocal imaging. Of note, while the mitochondrial network of $\mathrm{C} 13$ cells appeared scattered and less structured than in 2008 cells (Figure 2A, left panels), no differences in mitochondrial morphology between H2008 and HC13 were observed (Figure 2A, right panels). Importantly, $\mathrm{C} 13$ cells showed a dramatic decrease in mitochondrial mass measured by Nonyl-Acridine Orange (Figure 2B), which was consistent with a decrease in MTG staining with respect to their 2008 counterpart (Figure 2C). Since the expression of genes involved in mitochondrial 
Table 1: mtDNA sequence of human ovarian cancer cells

\begin{tabular}{|c|c|c|}
\hline \multicolumn{3}{|l|}{2008} \\
\hline POLYMORPHISM & GENE & VARIATION \\
\hline 66delG & MT-DLOOP & \\
\hline 309insC & MT-DLOOP & \\
\hline 315 insC & MT-DLOOP & \\
\hline \multicolumn{3}{|l|}{$379 \mathrm{~A}>\mathrm{T}$} \\
\hline $709 \mathrm{G}>\mathrm{A}$ & MT-RNR1 & non cod \\
\hline $1438 \mathrm{~A}>\mathrm{G}$ & MT-RNR1 & non cod \\
\hline $1888 \mathrm{G}>\mathrm{A}$ & MT-RNR2 & non cod \\
\hline $4769 \mathrm{~A}>\mathrm{G}$ & MT-ND2 & syn \\
\hline $6734 \mathrm{G}>A$ & MT-CO1 & syn \\
\hline $8860 \mathrm{~A}>\mathrm{G}$ & МТ-АТР6 & T-A \\
\hline $15287 \mathrm{~T}>\mathrm{C}$ & MT-CYB & F-L \\
\hline $15326 \mathrm{~A}>\mathrm{G}$ & MT-CYB & T-A \\
\hline $16519 \mathrm{~T}>\mathrm{C}$ & MT-DLOOP & \\
\hline
\end{tabular}

*30\% of mtDNA polymorphism rate in C13compared to 2008 cells.

${ }^{* *} 50 \%$ of mtDNA polymorphism rate in $\mathrm{C} 13$ compared to 2008 cells.

\section{C13}

\begin{tabular}{|c|c|c|}
\hline POLYMORPHISM & GENE & VARIATION \\
\hline 66delG & MT-DLOOP & \\
\hline $263 \mathrm{~A}>\mathrm{G}$ & MT-DLOOP & \\
\hline 315 insC & MT-DLOOP & \\
\hline \multicolumn{3}{|l|}{$379 \mathrm{~A}>\mathrm{T}$} \\
\hline $709 \mathrm{G}>\mathrm{A}$ & MT-RNR1 & non cod \\
\hline $1438 \mathrm{~A}>\mathrm{G}$ & MT-RNR1 & non cod \\
\hline $1888 \mathrm{G}>\mathrm{A}$ & MT-RNR2 & non cod \\
\hline $4769 \mathrm{~A}>\mathrm{G}$ & MT-ND2 & syn \\
\hline $6734 \mathrm{G}>\mathrm{A}$ & MT-CO1 & syn \\
\hline $\begin{array}{l}8156 \text { heteroplasmy } \\
G>T^{*}\end{array}$ & MT-CO2 & $\begin{array}{l}\text { V-L } \\
\mathbf{L D}=\mathbf{0 , 5 3}\end{array}$ \\
\hline $8860 \mathrm{~A}>\mathrm{G}$ & MT-ATP6 & T-A \\
\hline $\begin{array}{l}12018 \text { heteroplasmy } \\
C>T^{* *}\end{array}$ & MT-ND4 & $\begin{array}{l}T-I \\
L D=0,69\end{array}$ \\
\hline $\begin{array}{l}13828 \text { heteroplasmy } \\
\mathrm{C}>\mathrm{T}^{* *}\end{array}$ & MT-ND5 & $\begin{array}{l}\text { L-P } \\
\text { LD }=0,05\end{array}$ \\
\hline $14470 \mathrm{~T}>\mathrm{A}$ & MT-ND6 & syn \\
\hline $15287 \mathrm{~T}>\mathrm{C}$ & MT-CYB & F-L \\
\hline $15326 \mathrm{~A}>\mathrm{G}$ & MT-CYB & T-A \\
\hline $16519 \mathrm{~T}>\mathrm{C}$ & MT-DLOOP & \\
\hline
\end{tabular}

higher sensitivity to glucose deprivation (Figure 3C) and the incubation with the glycolysis inhibitor 2-Deoxyglucose (2DG) led to significant cell death of these cells (Figure 3D). To support these data we used also another cancer cell line (human cervix squamous cell line, A431) and its relative cisplatin resistant counterpart (A431pt). A431pt, similarly to C13, presented a higher glucose-dependency, increased GLUT1 expression, and major sensitivity to galactose medium (Supplementary Figure 2A-2D). Together, these results show that cisplatinresistant cells increase their demands of glucose and are more sensitive to inhibition of glycolysis, when compared to the cisplatin-sensitive counterpart.

Glutamine is a major source of carbons for the mitochondria of cancer cells $[21,22]$. In order to investigate the biosynthetic role of glutamine, we incubated $\mathrm{C} 13$ and 2008 cells with uniformly labelled $\left[\mathrm{U}-{ }^{13} \mathrm{C}\right]$ glutamine and analysed the isotopologue distribution of tricarboxylic acid (TCA) cycle intermediates. While the total pool of some TCA cycle intermediates, including succinate and malate, was lower in C13 than in 2008 cells (Figure 4A), the incorporation 
A

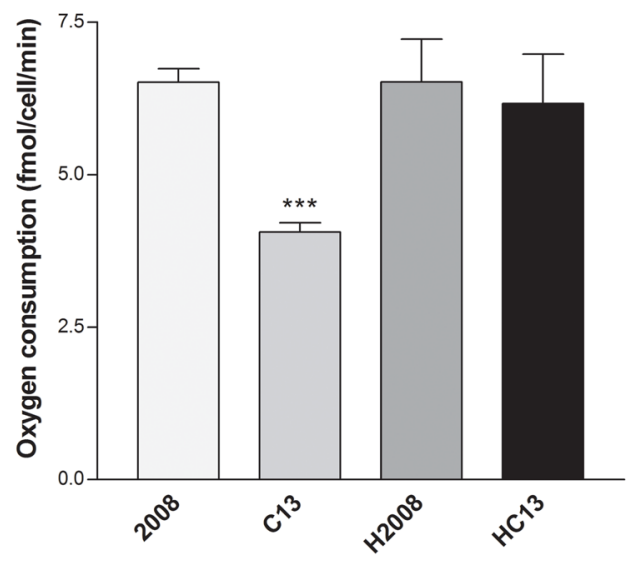

C

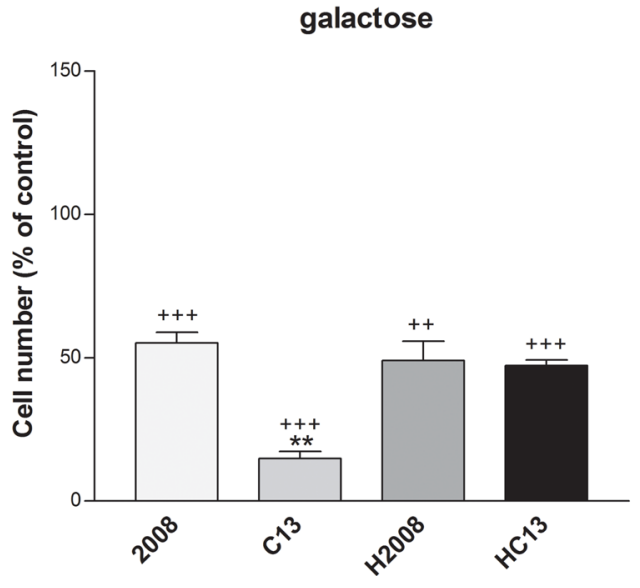

B

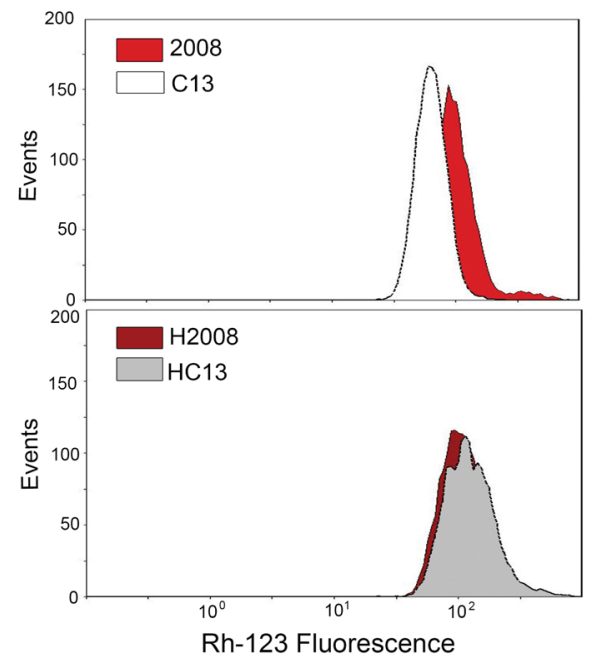

D

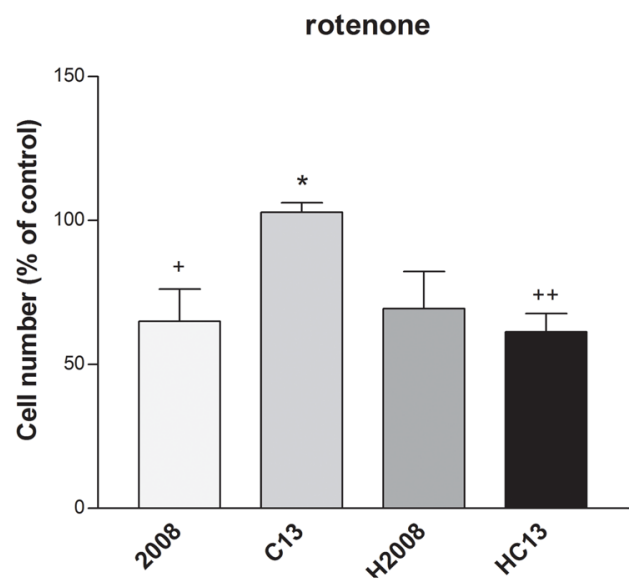

Figure 1: Mitochondrial function in cancer cisplatin-resistant cells and their derived cybrids. A. Oxygen consumption of ovarian cancer cells (2008-C13) and their derived cybrids (H2008-HC13). B. Representative plots of the mitochondrial potential ( $\Delta \Psi \mathrm{m})$ measured by flow cytometry. C. Effect of $5 \mathrm{mM}$ galactose and D. $0.1 \mu \mathrm{M}$ rotenone on cell viability after 24 hours of treatment. Data are expressed as percentage of cell number compared to the relative control. The data were obtained from at least 3-5 independent cultures. ${ }^{* * *} p<0.001,{ }^{*} p<0.01,{ }^{*} p<0.05 ; \mathrm{C} 13$ vs 2008. $+++p<0.001,++p<0.01,+p<0.05$; treatment $v s$ control.

of glutamine-derived carbons into glutamate, succinate, fumarate and malate was significantly higher in cisplatinresistant cells (Figure 4B). These results suggest that in the presence of deregulated mitochondrial function, glutamine becomes a privileged source of carbon for $\mathrm{C} 13$ cells. In line with a functional relevance of glutamine, C13 cells, differently from 2008 cells, showed a marked decrease in cell proliferation when cultured in glutamine-free media (Figure 4C and 4D).

Besides being a carbon source for the TCA cycle, glutamine is a key precursor of glutamate, required, among many functions, for the biosynthesis of glutathione (GSH), a major redox buffer in the cells.
GSH has been proposed as an important molecule to sustain cisplatin resistance, and the overexpression of enzymes involved in GSH biosynthesis has been documented in these cells [23]. Although GSH vs GSSG ratio was similar between $\mathrm{C} 13$ and 2008 cells (Supplementary Table 1), the amount of GSH and GSSG was significantly higher in $\mathrm{C} 13$ cells (Figure 5A-5B). Of note, the contribution of glutamine to $\mathrm{GSH}$ was increased in $\mathrm{C} 13$ cells (Figure 5C), suggesting that a portion of glutamine is used by cisplatin-resistant cells to sustain GSH biosynthesis. These results indicate that the metabolic reprogramming of cisplatin-resistant cells may contribute to redox buffering. 
A

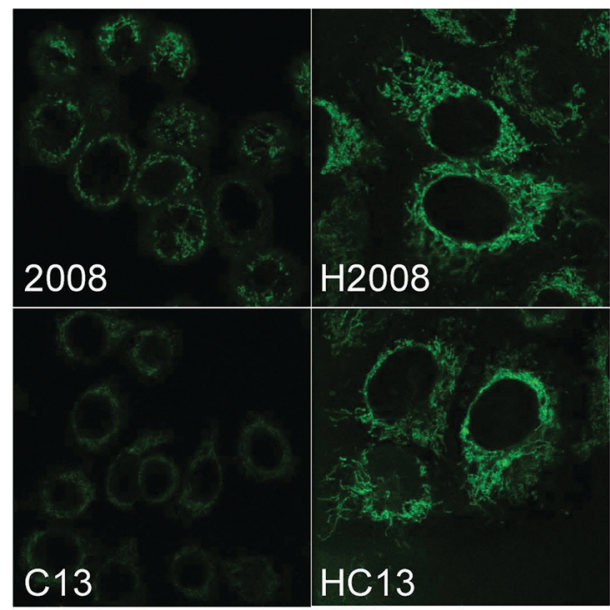

C

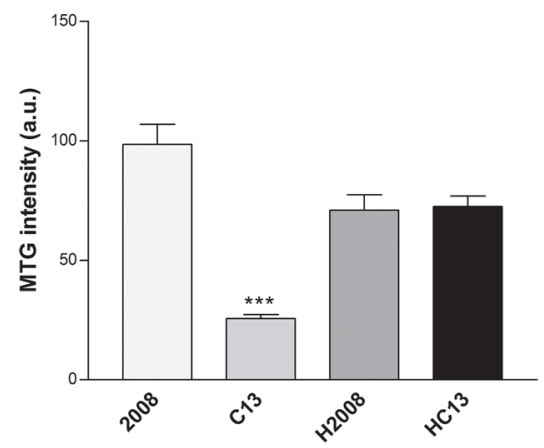

E

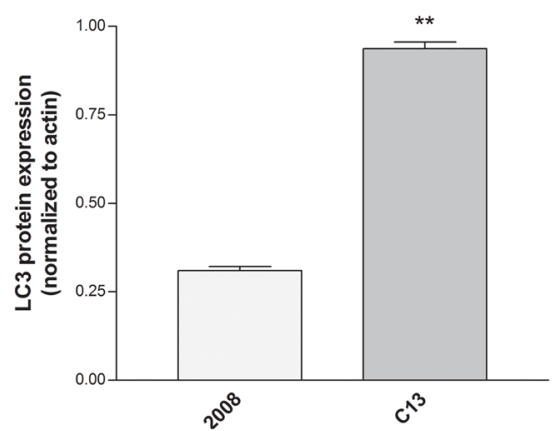

$\mathrm{B}$

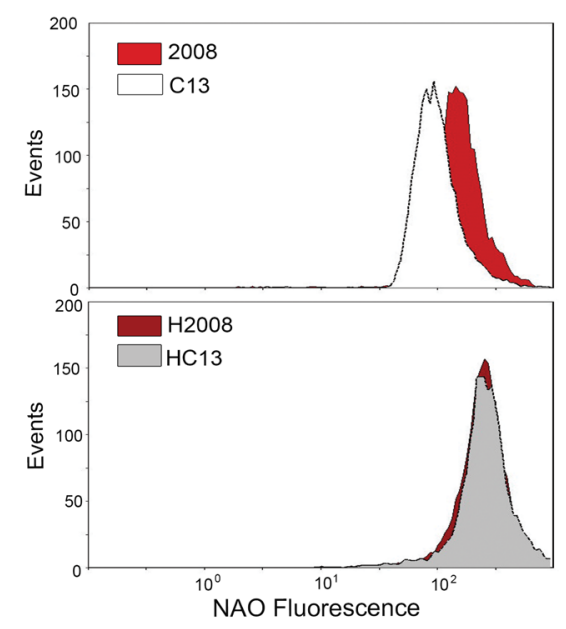

D

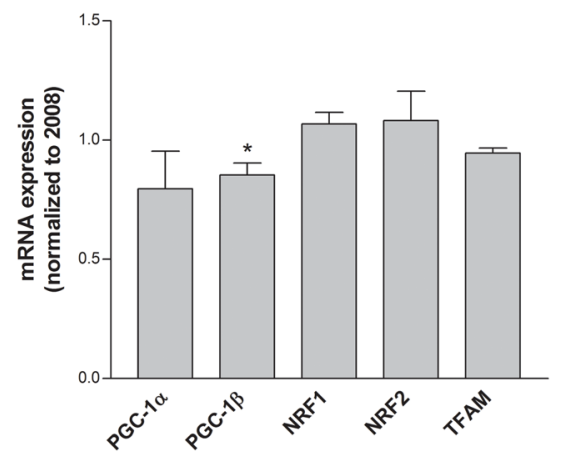

$\mathrm{F}$

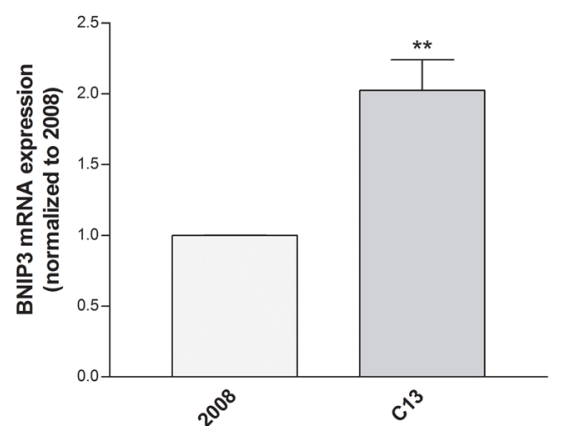

Figure 2: Cisplatin-resistant cells present a reduced mitochondrial mass. A. Representative confocal images of Mitotracker Green (MTG) staining. B. Representative plots of Acridine Orange 10-Nonyl bromide (NAO) mean fluorescence intensity measured by flow cytometry.C. MTG mean fluorescence intensity, calculated after a volumetric reconstruction of the mitochondrial network. D. Expression levels of genes involved in mitochondrial biogenesis or F. in mitophagy as tested by qRT-PCR. All genes were normalized to $\beta$-actin as endogenous control. E. LC3 protein expression measured from western blotting. The data were obtained from at least 3-5 independent cultures. ${ }^{* * *} p<0.001,{ }^{* *} p<0.01, * p<0.05 ; \mathrm{C} 13$ vs 2008.

\section{Inhibition of glucose-6-phosphate dehydrogenase (G6PDH) sensitizes cisplatin-resistant cells}

Several lines of evidence suggest that, to maintain redox homeostasis, cancer cells engage into the PPP, a major source of NADPH for the cells. We hypothesized that, in addition to increasing GSH biosynthesis, C13 cells might exploit the PPP pathway to compensate for the increased oxidative stress. G6PDH is a major checkpoint for the activity of the PPP. Interestingly, G6PDH mRNA (Figure 5D), protein expression (Figure 5E) and activity (Figure 5F), were increased in $\mathrm{C} 13$ cells, when compared to 2008. To better understand the relevance of this metabolic 


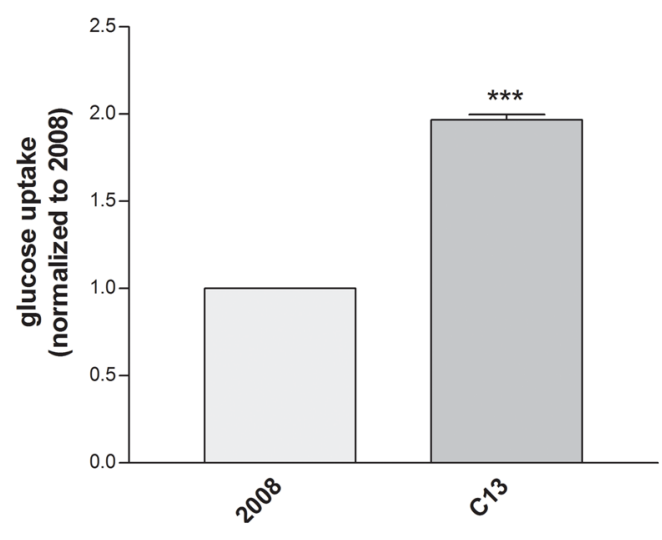

C

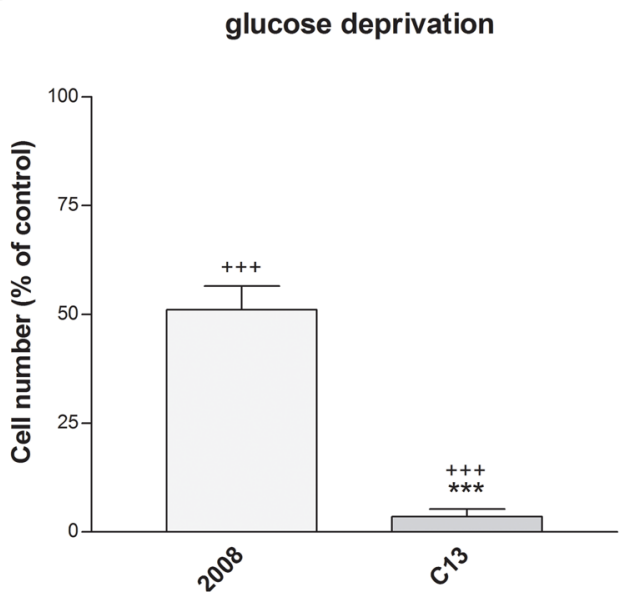

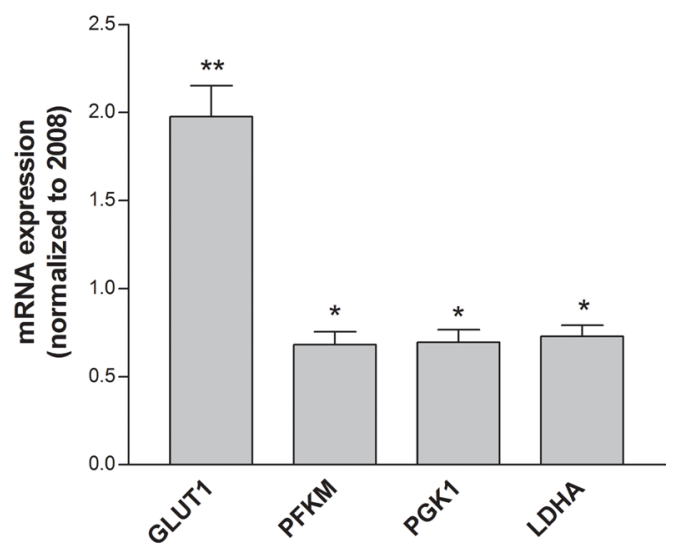

D

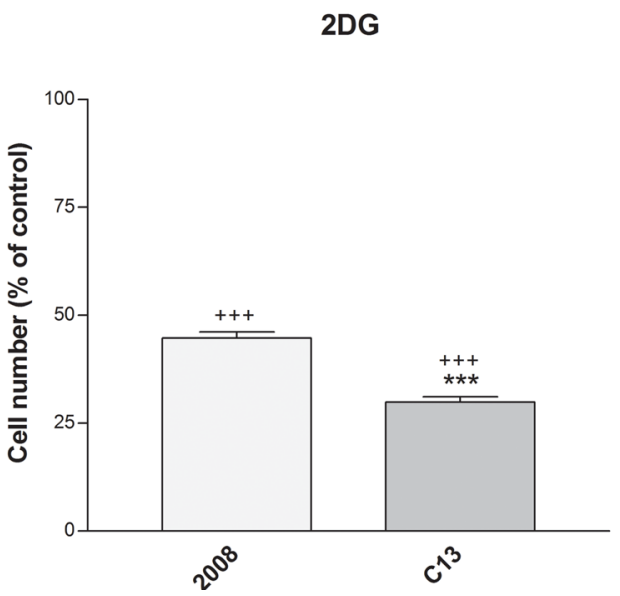

Figure 3: Cisplatin-resistant cells show an increased dependency to glucose. A. Glucose uptake measured after incubation with the glucose analogue 6-NBDG. Data are normalized to cisplatin-sensitivecells. B. Expression levels of glycolytic genes measured by qRT-PCR. All genes were normalized to $\beta$-actin. C-D. Cell viability after 24 hours of glucose deprivation with (D) or without (C) $1 \mathrm{mM}$ 2-DG. Data are expressed as percentage of cell number compared to control. The data were obtained from at least 3-4 independent cultures. $* * * p<0.001, * * p<0.01, * p<0.05 ; \mathrm{C} 13$ vs 2008. $+++p<0.001$; treatment $v s$ control.

pathway in cisplatin resistance, cells were incubated with a combination of 6-aminonicotinamide (6-AN, competitive G6PDH inhibitor [24]) or dehydroepiandrosterone (DHEA, uncompetitive G6PDH inhibitor [25]) and cisplatin at concentrations lower than $\mathrm{IC}_{50}$. In order to appropriately assess the effects of the combination of 6-AN or DHEA and cisplatin, we performed isobolographic analysis. The linearity of the iso-effective concentrations producing $25 \%$ of cytotoxic effect strongly indicates additivity (Figure 5G-5H). On the contrary, the cytotoxic effect on 2008 was only due to the prevalent cisplatin activity, which hindered the overall effect, so an isobolograph could not be generated. Of note also in A431pt G6PDH expression and mRNA were increased when compared to A431 (Supplementary Figure 3A-3B) similarly to $\mathrm{C} 13$. By performing isobolographic analysis on iso-effective concentrations of cisplatin and 6-AN or DHEA producing $25 \%$ of cytotoxic effect, in A431pt cells, the observed curves deviate from the theoretical line show additivity for 6-AN and a modest synergism for DHEA (Supplementary Figure 3C-3D). Taken together, these results suggest that cisplatin-resistant cells exploit the oxidative PPP as a resistance mechanism. Both resistant cell lines did not show cross-resistance with other chemotherapeutic agents, including paclitaxel and doxorubicin (see Supplementary Figure 4).

\section{DISCUSSION}

Cisplatin cytotoxicity has been originally ascribed to interactions between cisplatin and nuclear DNA, which lead to the formation of adducts that activate 
A

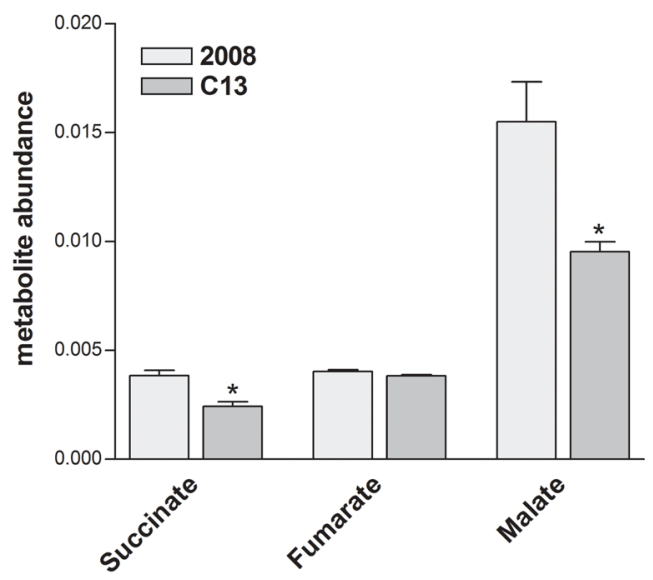

C

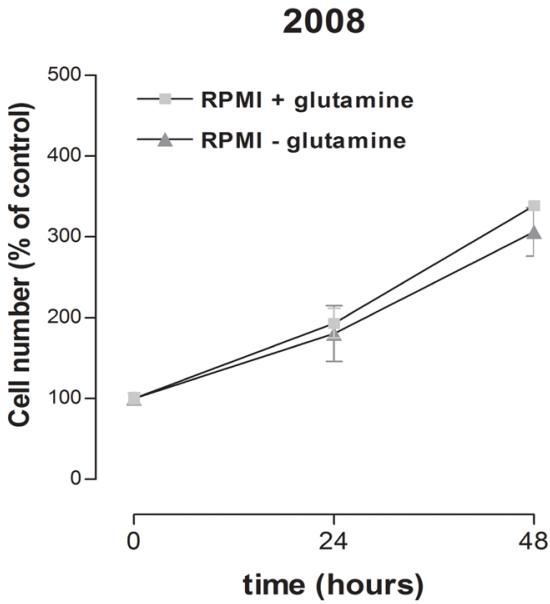

B

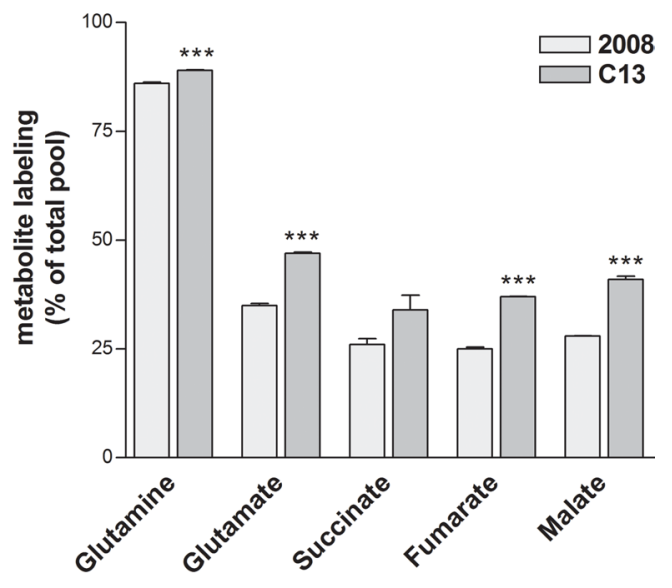

$\mathrm{D}$

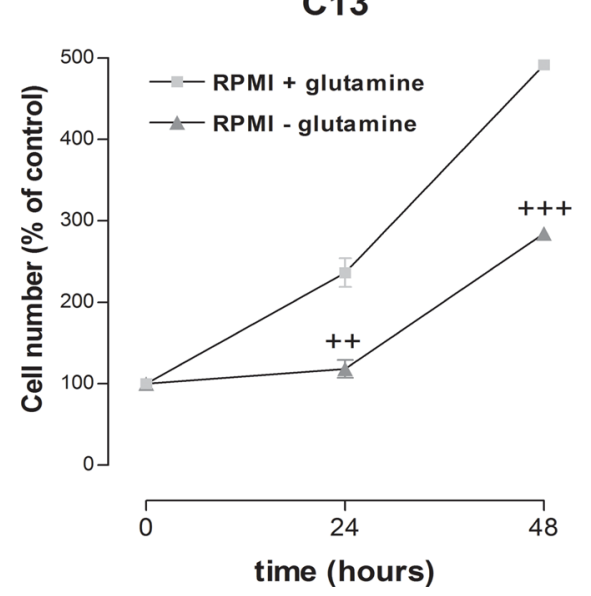

Figure 4: Cisplatin-resistant cells present an increased dependency on glutamine for TCA intermediates biosynthesis. A. Abundance of TCA intermediates measured using LC-MS normalised to total ion current. B. Incorporation of ${ }^{13} \mathrm{C}$-labelled carbons into glutamate, succinate, fumarate and malate after growing cells for 24 hours in the presence of $\left[\mathrm{U}{ }^{-13} \mathrm{C}\right]$ glutamine. C-D. Effect of glutamine deprivation on 2008 (C) and C13 (D) cell viability measured by trypan blue exclusion assay. The data were obtained from at least three independent cultures. ${ }^{* * *} p<0.001,{ }^{*} p<0.05 ; \mathrm{C} 13$ vs 2008 . ${ }^{+++} p<0.001,++p<0.01$; treatment $v s$ control.

the apoptotic machinery [2]. More recent data suggest that only $5-10 \%$ of cisplatin is bound to DNA, whilst other nucleophilic molecules such as phospholipids, cytoskeletal and membrane proteins, and mtDNA are targeted by the drug, suggesting that other mechanisms may explain cisplatin toxicity [26, 27]. Unfortunately, the therapeutic effectiveness of cisplatin is limited by the onset of cisplatin resistance [7], whose mechanisms are still not fully understood. Emerging evidence supports the idea that the deregulated cell metabolism could sustain drug resistance [28]. In this work we have investigated the contribution of metabolic reprogramming to cisplatin resistance and revealed novel metabolic liabilities of cisplatin-resistant cells.
Our previous research showed that cisplatinresistant ovarian cancer cells (C13) present defective mitochondrial bioenergetics $[12,20]$. By generating transmitochondrial hybrids $[29,30,31]$ we demonstrate here that the mitochondrial polymorphisms found in $\mathrm{C} 13$ cells are not causative of the different mitochondrial asset previously observed. We also show that $\mathrm{C} 13$ mitochondrial dysfunction is not due to inherent respiratory chain defects but, rather, by a decrease in mitochondrial biomass. The increased mitochondrial turnover may be required to clear dysfunctional mitochondria that accumulate in cancer cells, and to maintain mitochondrial metabolism, as recently proposed by Strohecker et al. [32]. In line with these findings, we observed that the metabolic activity 
A

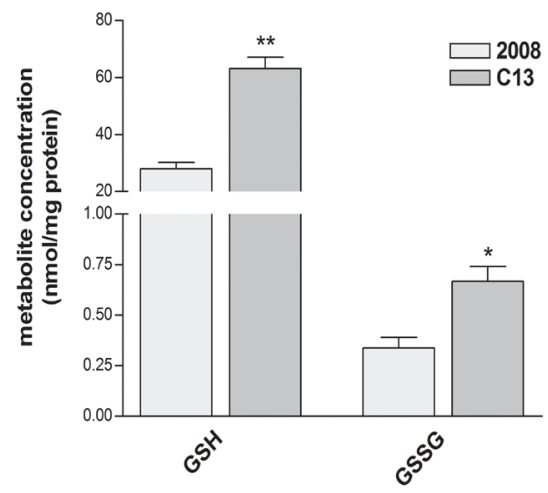

D

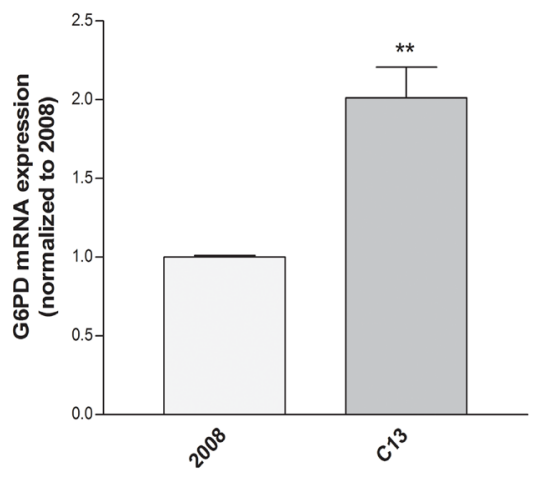

G

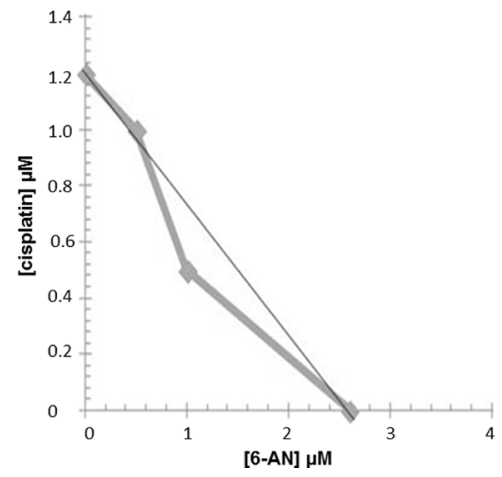

B
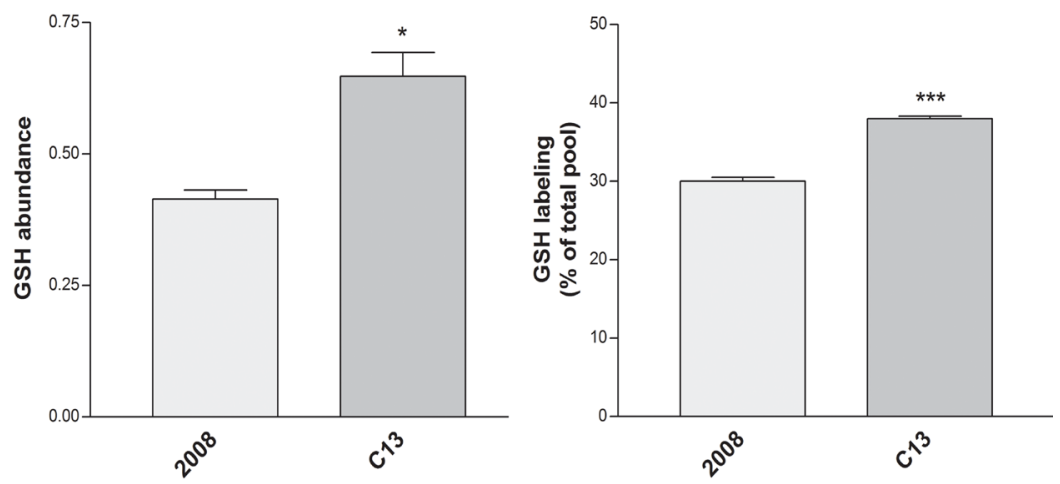

$\mathrm{E}$
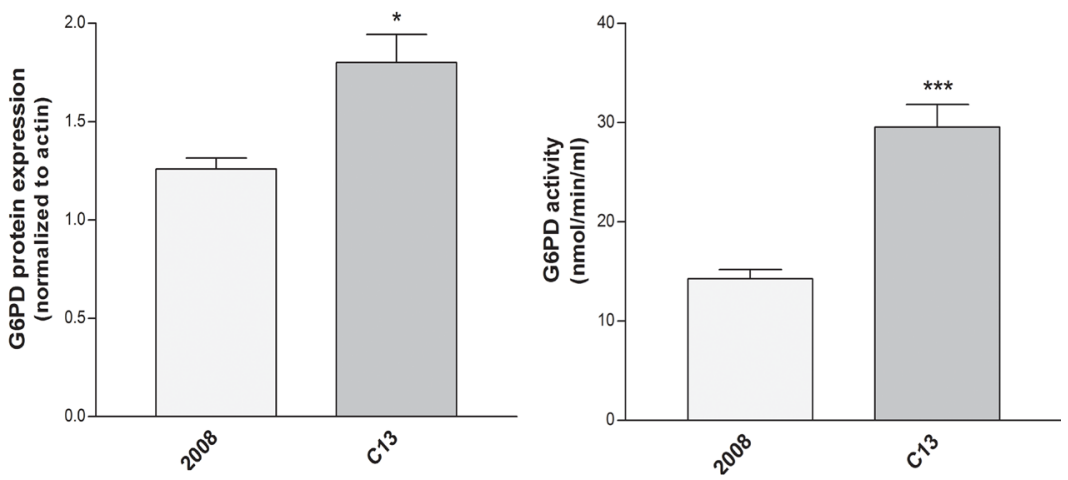

$\mathrm{H}$

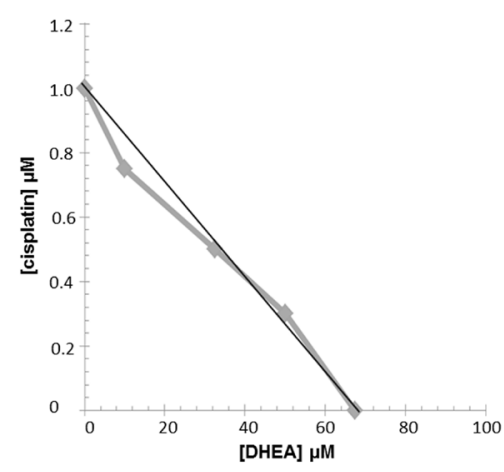

Figure 5: Redox homeostasis is required for survival of C13 cisplatin-resistant cells. A-B. Cellular GSH and GSSG content measured by enzymatic assay (A) and GSH abundance (normalised to total ion count) measured by LC-MS (B). C. Intracellular levels of ${ }^{13} \mathrm{C}_{5}$-GSH after growing cells for 24 hours in the presence of $\left[\mathrm{U}_{-}{ }^{13} \mathrm{C}\right]$ glutamine. Data are normalized on the total pool of intracellular GSH (B) D. G6PD mRNA levels quantified by qRT-PCR, E. protein expression measured by western blotting and F. G6PDH enzymatic activity of 2008 and C13 cells. G-H. Isobologram of cisplatin-resistant cells showing additive effect of 6-AN or DHEA in association with cisplatin treatment. Data are expressed as percentage of cell number compared to control. The graph was obtained using iso-effective drug concentrations causing $25 \%$ of cytotoxic effect. Straight line indicates the theoretical additivity line. The data were obtained from at least $3-5$ independent cultures. ${ }^{* * *} p<0.001,{ }^{* *} p<0.01,{ }^{*} p<0.05$; C13 vs 2008. ${ }^{+++} p<0.001$; treatment $v s$ control. 
of $\mathrm{C} 13$ cells measured by incubating cells with [U- $\left.{ }^{13} \mathrm{C}\right]$ glutamine is even higher than the cisplatin-sensitive counterpart. Therefore, our results suggest that a high mitochondrial turnover could compensate for inherent mitochondrial defects in cisplatin-resistant cells.

We then analyzed other aspects of the metabolic reprogramming of cisplatin-resistant cells, including glycolysis, glutaminolysis, and metabolic pathways involved in redox homeostasis. Cisplatin-resistant cells exhibited increased glucose uptake, overexpression of the glucose transporter GLUT1, and increased glutaminolysis, which make these cells more sensitive to glucose and glutamine deprivation. It is worth noting that glucose and glutamine are not mere carbon sources but they also contribute to the redox homeostasis of these cells. The activation of antioxidant pathways is now emerging as a crucial adaptive mechanism involved in drug resistance and a role for increased GSH biosynthesis has been proposed to provide resistance to cisplatin [23, 33, 34]. Consistent with this view, we found that glutaminederived glutamate is utilized for GSH biosynthesis in cisplatin-resistant cells. In support of a metabolic rewiring of glucose towards antioxidant pathways, we found that the expression and enzymatic activity of G6PDH, a key enzyme of the PPP, were elevated in resistant cells as compared to sensitive cells. Moreover, the combined treatment with the G6PDH inhibitors 6-AN or DHEA and cisplatin, showed a selective additive effect on cisplatin-resistant cells, suggesting that upregulation of G6PDH activity could be a targetable mechanism of chemotherapeutic resistance to cisplatin. In leukemia cells, it has been documented that the acquisition of daunorubicin resistance is accompanied by elevation of the oxidative PPP. But adriamycin/doxorubicinresistant MCF-7 cells display reduced G6PDH and PPP activity compared with sensitive cells, suggesting that a hyperactive PPP sensitizes cells to anthracyclines [17]. Differently from the contradictory results obtained with anthracyclines, our data clearly indicate that the PPP inhibition may be peculiar for cisplatin resistance, offering a novel synthetic lethality approach. These results are in line with the concept of induced essentiality, where by cancer cells become sensitive to the inhibition of the very same metabolic pathways that evolved as mechanisms of resistance from chemotherapeutic agents [35, 36].

Taken together our results show that profound metabolic changes underpin cisplatin resistance. Besides reduction of mitochondrial mass and overall mitochondrial function, these cells increase their demand of glucose and glutamine, which are in part used to maintain the cell's antioxidant defenses. Chemotherapy designed to target metabolic pathways is a new approach, and potentially more effective to inhibit tumor cell growth [37]. Our work demonstrated that the combination of cisplatin treatment with inhibition of the PPP enzyme G6PDH, can remarkably improve the cytotoxic effects of cisplatin and can help to overcome cancer resistance to cisplatin treatment.

\section{MATERIALS AND METHODS}

\section{Cell lines}

Human ovarian carcinoma cell lines (2008 wild type and C13 cisplatin-resistant cells) were grown in Roswell Park Memorial Institute medium (RPMI 1640) supplemented with $10 \%$ fetal bovine serum (FBS), $4 \mathrm{mM}$ glutamine, $100 \mathrm{U} / \mathrm{ml}$ penicillin and $100 \mu \mathrm{g} / \mathrm{ml}$ streptomycin, in humidified condition at $5 \% \mathrm{CO}_{2}$ and $37^{\circ} \mathrm{C}$.

206- $\rho^{\circ}$ cells derived from mtDNA depletion of 143B-TK ${ }^{-}$osteosarcoma cells (kind gift of Andrea Martinuzzi, IRCSS E. Medea-La Nostra Famiglia association) were cultured as previously described [38].

Transmitochondrial cybrid cell lines (H2008 and HC13) were generated by polyethylene glycol fusion of enucleated 2008 and C13 with the mtDNA-less $\left(\rho^{0}\right)$ osteosarcoma (143B-TK ${ }^{-}$) cell line as previously described [38]. Individual hybrid clones were isolated 10-20 days later using glass cylinders. Hybrid cell lines were cultured as previously described [39]. All reagents for cell culture were from Cambrex-Lonza (Basel, Switzerland) and FBS from Gibco, Invitrogen (Carlsbad, CA, USA).

\section{Genome sequences}

The entire mitochondrial genome was sequenced in a series of overlapping fragments using M13-tagged oligodeoxynucleotide primers to facilitate direct sequencing of the PCR amplified products with BigDye ${ }^{\mathbb{}}$ terminator chemistries on an Applied Biosystem 3100 automated sequencer (Applied Biosystems, Warrington, UK) [40]. All sequences were directly compared to the revised Cambridge reference sequence for human mtDNA (GenBank Accession number NC_012920).

\section{Cell viability assays}

\section{Trypan blue exclusion assay}

$2 \times 10^{5}$ cells $(2008-\mathrm{C} 13)$ or $1 \times 10^{5}$ cells $(\mathrm{H} 2008$ HC13) were plated on 6-well plates and, following overnight incubation, were exposed to different treatments according to experimental protocols. After treatments, cells were washed, detached with $0.25 \%$ trypsin- $0.2 \%$ EDTA and suspended in trypan blue (Sigma-Aldrich, St Louis, MO, USA) at 1:1 ratio in medium solution. Cells were counted using a chamber Burker hemocytometer.

\section{Sulforhodamine B (SRB) test}

$2.5 \times 10^{3}$ cells were plated on 96-well plates and, following overnight incubation, were exposed to different treatments according to experimental protocols. After treatments cells were fixed to tissue-culture plates with trichloroacetic acid (Sigma-Aldrich) and stained for 30 minutes with SRB (Sigma-Aldrich). The bound SRB was dissolved by adding $160 \mu \mathrm{l}$ of $10 \mathrm{mM}$ TRIS 
$(\mathrm{pH}=10.5)$ and the absorbance was measured at $570 \mathrm{~nm}$ using a Victor3X multilabel plate counter (Wallac Instruments, Turku, Finland).

\section{Annexin V/propidium iodide staining}

$1 \times 10^{5}$ cells $(\mathrm{H} 2008-\mathrm{HC} 13)$ were seeded in 12-well plates, incubated overnight and treated with cisplatin $(1-10 \mu \mathrm{M})$ for 24 hours. Then, cells were harvested by quick trypsinization and centrifugated at $1200 \mathrm{rpm}$ for 5 minutes. The cell pellet was resuspended in a binding buffer containing Alexa Fluor 488 Annexin V and propidium iodide (Molecular Probes, Invitrogen, Carlsbad, CA, USA) and then incubated for 15 minutes at room temperature as previously described [12]. The fluorescence of stained cells was measured by Epics XL flow cytometer (Coulter Systems, Fullerton, CA, USA) and analysed with the EXPO 32 software (Coulter Systems, Fullerton, CA, USA).

\section{Oxygen consumption}

Oxygen consumption was measured in live cells $\left(3.5 \times 10^{6}\right)$ resuspended in $1 \mathrm{ml}$ glucose-free DMEM (Gibco, Invitrogen) supplemented with $10 \%$ sodiumpyruvate (Cambrex-Lonza) at $37^{\circ} \mathrm{C}$, using a Clark-type oxygen electrode (Hansatech Instruments, King's Lynn, Norfolk, UK). Oxygen consumption was measured using the software Oxygraph plus v. 1.01. Data processing includes: $\mathrm{fmol} / \mathrm{c} / \mathrm{min}=\left(\mathrm{RATE} / 3.5 \times 10^{6}\right) * 1$ million.

\section{Mitochondrial membrane potential $(\Delta \Psi)$ and mitochondrial mass}

\section{Flow cytometry}

$2 \times 10^{5}$ cells $(2008-\mathrm{C} 13)$ or $1 \times 10^{5}$ cells $(\mathrm{H} 2008$ HC13) were seeded and incubated for 48 hours, washed with phosphate buffer saline solution (PBS), detached with $0.25 \%$ trypsin- $0.2 \%$ EDTA and centrifuged for 5 minutes at $1200 \mathrm{rpm}$. Cells were resuspended with rhodamine-123 $(10 \mu \mathrm{M})$ or Acridine Orange 10-Nonyl bromide NAO $(25 \mathrm{nM})$ and incubated for 15 minutes. Probes were from Sigma-Aldrich. Fluorescence intensity was analyzed using an Epics XL flow cytometer. $10^{4}$ cells of interest were analyzed. Mean fluorescence intensity (MFI) values were obtained using the EXPO 32 software.

\section{Live-cells confocal microscopy}

$2 \times 10^{5}$ cells $(2008-\mathrm{C} 13)$ or $1 \times 10^{5}$ cells $(\mathrm{H} 2008$ HC13) were grown in $3.5 \mathrm{~cm}$ glass-bottom dishes (MatTek Corporation, Ashland, USA) and, after 48 hours, were loaded with $100 \mathrm{nM}$ Mitotracker Green (MTG; Invitrogen). Cells were imaged using a laser scanner microscope (Leica TCS SP5, 60X magnification). A volumetric reconstruction was then obtained and analysed using the software Volocity.

\section{Immunoblot assay}

$1.5 \times 10^{6}$ cells $(2008-\mathrm{C} 13)$ were plated in $100 \mathrm{~mm}$ cell culture dish and allowed to attach overnight. After 48 hours, cells were lysed with ice-cold lysis buffer supplemented with the protease inhibitor cocktails (Roche Molecular Biochemicals, Mannheim, Germany). The protein content was determined by Lowry procedure (Bio-rad DC Protein Assay, MA, USA). Equal amounts of protein $(40 \mu \mathrm{g})$ were loaded on a polyacrylamide gel and electrophoretically separated in running buffer. After electrophoresis, the proteins were blotted onto an Hybond-P PVDF membrane (Amersham Biosciences, Buckinghamshire, UK). After blocking, the membrane was exposed to the elected primary antibodies: anti-LC3 (1:1000; Cell Signaling, MA, USA) or anti-G6PD (1:500; Santa Cruz Biotechnology, Inc., Europe). After washing, the membrane was incubated with HRP-conjugated anti-rabbit secondary antibody (1:3500; PerkinElmer, MA,USA). The signal was visualized with enhanced chemoluminescent kit (Amersham Biosciences) according to the manufacturer's instructions and analyzed by Molecular Imager VersaDoc MP 4000 (Bio-rad). LC3 and G6PD were normalized to beta-actin (1:7000; AbCam, Cambridge, UK).

\section{Quantitative real-time PCR}

Total mRNA was isolated as per manufacturer's instructions using QIAshredder and RNeasykits (Qiagen, Venlo, Netherlands) and measured with a NanoDrop ND1000 spectrophotometer (NanoDrop Technologies, Inc. Wilmington, DE, USA). $0,5 \mu \mathrm{g}$ of total mRNA was reversetranscribed to complementary DNA using The High Capacity cDNA Reverse Transcription Kits of Applied Biosystem by Life Technologies. The relative expression of genes of interest was determined by quantitative real-time PCR (StepOne ${ }^{\mathrm{TM}}$ Systems of Applied Biosystem by Life Technologies) using Power SYBR ${ }^{\circledR}$ Green PCR Master Mix (Applied Biosystem by Life Technologies) and the primers designed as follow: BNIP3: F gaatttctgaaagttttcettcca R ttgtcagacgecttccaata; GLUT1: F ttaactccacccacctcct, R ccaaatcggcatcttctcat; PFKM: F gccatcagcctttgacaga, R ctccaaaagtgccatcactg; PGK1: F cagctgctgggtctgtcat, $\mathrm{R}$ gctggctcggctttaacc; LDHA: F aaaccgtgttattggaagcg, $\mathrm{R}$ agcactctcaaccacctgct. To measure the mRNA level of G6PDH and mitochondrial biogenesis genes, total mRNA was isolated with TRIzol (Life Technologies) as previously described by Chomczynski $\mathrm{P}$ and Sacchi $\mathrm{N}$ [42] and measured with a Beckman Coulter DU-800 spectrophotometer. The relative expression of each gene was determined by quantitative real-time PCR $\left(\mathrm{Eco}^{\mathrm{TM}}\right.$ Illumina, Real-Time PCR system, San Diego, CA, USA) using One Step SYBR PrimeScript RT-PCR Kit (Takara Bio, Inc., Otsu, Shiga, Japan) and the primers designed as follow: G6PDH: $\mathrm{F}$ aagaacgtgaagctccetga 
$\mathrm{R}$ aatataggggatgggcttgg; PGC-1 $\alpha$ : F acacagtcgcagtcacaacac R ggagtggtgggtggagttagg; PGC-1 $\beta$ : F gcacctcacctcggcacag R cggctccttgtcctcettgg; NRF1: F gtaaccetgatggcactgtctc R gettgcgtcgtctggatgg; NRF2: F ttccttcagcagcatcctctcc R aatctgtgttgactgtggcatctg; Tfam: F aacaacgaaaatatggtgctgagg $\mathrm{R}$ caagtattatgctggcagaagtcc. Linearity and efficiency of PCR amplifications were assessed using standard curves generated by serial dilution of complementary DNA; melt-curve analysis was used to confirm the specificity of amplification and absence of primer dimers. All genes were normalized to $\beta$-actin designed as follow: $\mathrm{F}$ ccaaccgcgagaagatga $\mathrm{R}$ ccagaggcgtacagggatag. Expression levels of the indicated genes were calculated by the $\Delta \Delta \mathrm{Ct}$ method using respectively the dedicated StepOne software or Eco ${ }^{\text {TM }}$ Software v4.0.7.0.

\section{Liquid chromatography-mass spectroscopy (LC-MS)}

$2 \times 10^{5}$ cells $(2008-C 13)$ were plated in 6-well plates and after 48 hours quickly washed with ice cold PBS on an ice bath. The samples were therefore prepared as previously described [43]. In brief, cells were lysed with a dry ice/methanol solution $\left(-80^{\circ} \mathrm{C}\right)$ of $50 \%$ methanol $/ 30 \%$ acetonitrile in water and quickly scraped. The extracts were mixed at $4^{\circ} \mathrm{C}$ for 15 minutes and pelleted in a cooled centrifuge $\left(4^{\circ} \mathrm{C}\right)$. The supernatant was collected and submitted for LC-MS analysis. The amount of extraction solution was calculated according to the number of cells present in the sample dish, extrapolated using a "counter dish" cultured in the same conditions of the sample dishes. A concentration of $1 \mathrm{ml}$ per $1 \times 10^{6}$ cells was used in the extraction solutions.

Intermediates were separated using a liquid chromatography system. Data acquisition was controlled with Xcalibur 2.0 (ThermoElectron Co, San Jose, CA, USA). The mass accuracy was maintained below $1 \mathrm{ppm}$ due to use of a lock mass. The raw chromatograms were then aligned using the software SIEVETM (ThermoElectron). The integration of the measured ion current over a metabolite's elution time and $\mathrm{m} / \mathrm{z}$ interval is directly proportional to its absolute abundance in the solution. We manually removed from the SIEVE's output unspecific and misaligned peaks to eliminate the noise.

\section{Glucose uptake}

$5 \times 10^{3}$ cells $(2008-C 13)$ were plated in 96-well plate and allowed to attach overnight. After 24 hours, glucose uptake was measured by incubating cells with $90 \mu \mathrm{M}$ glucose analogue 6-NBDG (Invitrogen, Paisley, UK) for 1 minute. Cells where then washed, added with PBS and their fluorescence ( $\lambda$ ex: $465 \mathrm{~nm}, \lambda$ em: 540nm) was measured by Victor3X multilabel plate counter (Wallac Instruments).

\section{GSH/GSSG}

Cellular GSH and GSSG content was enzymatically determined as previously described by Floreani et al. [44]. $1.5 \times 10^{6}$ cells $(2008-\mathrm{C} 13)$ were plated in 100 $\mathrm{mm}$ cell culture dish and allowed to attach overnight. After 48 hours, cells were washed with PBS and then treated with 6\% meta-phosphoric acid (MPA). After 10 minutes at room temperature, the acid extract was collected, centrifuged for 5 minutes at $14000 \mathrm{rpm}$ and processed. The cellular pellet was solubilized with $0.5 \mathrm{M}$ potassium hydroxide and assayed for protein content. For total GSH determination, the above acid extract was diluted in $6 \%$ MPA and added with $0.1 \mathrm{M}$ potassium phosphate/5 mMEDTAbuffer(pH7.4), 10mM5,5-dithiobis(2-nitrobenzoic acid) and $5 \mathrm{mM}$ NADPH. After a 3 minute equilibration period, the reaction was started by adding 2 U GSH reductase (type III; Sigma-Aldrich; from baker's yeast; diluted in $0.1 \mathrm{M}$ phosphate/EDTA buffer). Product formation was recorded continuously at $412 \mathrm{~nm}$ with a Beckman DU800 UV-Vis spectrophotometer. The total amount of GSH was determined from a standard curve obtained by plotting known amounts of GSH against the rate of change in absorbance. For GSSG measurement, soon after preparation, the supernatant of acid extract was treated for derivatization with 2-vinylpyridine and triethanolamine. The samples were incubated at room temperature for 60 minutes and then assayed with the same procedure above described for total GSH measurement. The GSH concentration of each sample was calculated as the difference between total glutathione and GSSG. All reagents were from Sigma-Aldrich.

\section{G6PDH activity}

$1.5 \times 10^{6}$ cells $(2008-\mathrm{C} 13)$ were plated in $100 \mathrm{~mm}$ cell culture dish and allowed to attach overnight. After 48 hours, cells were washed with PBS and quickly scraped. $2.5 \times 10^{6}$ of cells were then collected by centrifugation and sonicated on ice. The G6PDH activity was assayed on cell supernatant as per manufacturer's instructions using the Glucose-6-Phosphate Dehydrogenase Activity Assay Kit (Cayman Chemical Company, MI, USA). The fluorescence intensity $(\lambda \mathrm{ex} / \mathrm{em}=540 / 585)$ was measured using a Victor3X multilabel plate counter (Wallac Instruments). The G6PDH activity ( $\mathrm{nmol} / \mathrm{min} / \mathrm{ml}$ ) was calculated as per manufacturer's instructions.

\section{Statistical analyses}

All data are expressed as mean \pm SEM. Standard ANOVA procedures followed by multiple pairwise comparison adjusted with Bonferroni corrections were performed for cell viability assays. Unpaired Student's $t$-tests were used to analyse all the other results. Significance was considered at $p<0.05$. 


\section{Isobolographic analysis}

Isobolographic analysis was used to determine the effect of the combination between cisplatin and the G6PDH inhibitor 6-AN or DHEA. Isoboles are defined as iso-effect curves that show drug concentrations resulting in equal effect $[45,46]$. From iso-effective curves it is possible to verify the presence of simple additivity, supra-additivity (synergism, i.e. when drug combination produces an effect greater than that predictable from each drug alone) or infra-additivity (antagonism). Isobolographic analysis was possible only for C13 and A431pt data; in 2008 cells the predominant effect produced by cisplatin hindered the overall effect.

\section{ACKNOWLEDGMENTS}

We thank Stefano Lovison for computer assistance.

\section{FUNDING}

This work was financially supported by PRAT (University of Padova), grant no. CPDA124517/12 and MIUR grant no 60A04-0443. DC fellowship was supported by grant no. CPDR134012. AR was supported by the AIRC grant no. IG 15863 and by the University of Padova grant no. CPDA 123598.

\section{CONFLICTS OF INTEREST}

The authors declare no conflict of interest.

\section{REFERENCES}

1. Galanski M. Recent developments in the field of anticancer platinum complexes. Recent Patents Anticancer Drug Discovery. 2006; 1:285-95.

2. Wang D, Lippard S. Cellular processing of platinum anticancer drugs. Nature Reviews Drug Discovery. 2005; 4:307-320.

3. Preston TJ, Abadi A, Wilson L, Singh G. Mitochondrial contribution to cancer cell physiology: potential for drug development. Advanced Drug Delivery Reviews. 2001; 49:45-61.

4. Galluzzi L, Senovilla L, Vitale I, Michels J, Martins I, Kepp O, Castedo M, Kroemer G. Molecular mechanisms of cisplatin resistance. Oncogene. 2012; 31:1869-83.

5. Ciscato F, Sciacovelli M, Villano G, Turato C, Bernardi $P$, Rasola A, Pontisso P. SERPINB3 protects from oxidative damage by chemotherapeutics through inhibition of mitochondrial respiratory complex I. Oncotarget. 2014; $5: 2418-27$.

6. Pasetto LM, D'Andrea MR, Brandes AA, Rossi E, Monfardini S. The development of platinum compounds and their possible combination. Critical Reviews In Oncology. Hematology. 2006; 60:59-75.
7. Koberle B, Tomicic MT, Usanova S, Kaina B. Cisplatin resistance: preclinical findings and clinical implications. Biochimica et Biophysica Acta. 2010; 1806:172-82.

8. Rabik CA, Dolan ME. Molecular mechanisms of resistance and toxicity associated with platinating agents. Cancer Treatment Reviews. 2007; 33:9-23.

9. Boulikas T, Vougiouka M. Cisplatin and platinum drugs at the molecular level. (Review). Oncology Reports. 2003; 10:1663-82.

10. Shen DW, Pouliot LM, Hall MD, Gottesman MM. Cisplatin Resistance: A Cellular Self-Defense Mechanism Resulting from Multiple Epigenetic and Genetic Changes. Pharmacological Reviews. 2014; 64:706-721.

11. Kelland LR. Preclinical perspectives on platinum resistance. Drugs. 2000; 59:1-8. discussion 37-8.

12. Montopoli M, Ragazzi E, Froldi G, Caparrotta L. Cell-cycle inhibition and apoptosis induced by curcumin and cisplatin or oxaliplatin in human ovarian carcinoma cells. Cell Proliferation. 2009; 42:195-206.

13. Ishikawa T, Ali-Osman F. Glutathione-associated cisdiamminedichloroplatinum (II) metabolism and ATPdependent efflux from leukemia cells. Molecular characterization of glutathione-platinum complex and its biological significance. Journal of Biological Chemistry. 1993; 268:20116-20125.

14. Vander Heiden MG, Cantley LC, Thompson CB. Understanding the Warburg Effect: The Metabolic Requirements of Cell Proliferation. Science. 2009; 324:1029-1033.

15. Hanahan D, Weinberg RA. Hallmarks of Cancer: The Next Generation. Cell. 2011; 144:646-674.

16. Menedez JM. Fine-tuning the lipogenic/lipolytic balance to optimize the metabolic requirements of cancer cell growth: molecular mechanisms and therapeutic perspectives. Biochimica et Biophysica Acta. 2010; 1801:381-391.

17. Patra KC, Hay N. The pentose phosphate pathway and cancer. Trends in Biochemical Sciences. 2014; 39:347-354.

18. Saiati LM, Amir-Ahmady B. Dietary regulation of expression of glucose-6-phosphate dehydrogenase. Annual Review of Nutrition. 2001; 21:121-40.

19. Jiang P, Du W, Wu M. Regulation of the pentose phosphate pathway in cancer. Protein Cell. 2014; 5:592-602.

20. Montopoli M, Bellanda M, Lonardoni F, Ragazzi E, Dorigo P, Froldi G, Mammi S, Caparrotta L. "Metabolic reprogramming" in ovarian cancer cells resistant to cisplatin. Current Cancer Drug Targets. 2011; 11:226-35.

21. Wise DR, Ward PS, Shay JE, Cross JR, Gruber JJ, Sachdeva UM, Platt JM, DeMatteo RG, Simon MC, Thompson CB. Hypoxia promotes isocitrate dehydrogenasedependent carboxylation of $\alpha$-ketoglutarate to citrate to support cell growth and viability. Proceedings of the National Academy of Science. 2011; 108:19611-19616.

22. Metallo CM, Gameiro PA, Bell EL, Mattaini KR, Yang J, Hiller K, Jewell CM, Johnson ZR, Irvine DJ, 
Guarente L, Kelleher JK, Vander Heiden MG, Iliopoulos $\mathrm{O}$, et al. Reductive glutamine metabolism by IDH1 mediates lipogenesis under hypoxia. Nature. 2012; 481:380-384.

23. Byun SS, Kim SW, Choi H, Lee C, Lee E. Augmentation of cisplatin sensitivity in cisplatin-resistant human bladder cancer cells by modulating glutathione concentrations and glutathione-related enzyme activities. BJU International. 2005; 95:1086-90.

24. Köhler E, Barrach H, Neubert D. Inhibition of NADP dependent oxidoreductases by the 6-aminonicotinamide analogue of NADP. FEBS Letters. 1970; 6:225-8.

25. Raineri R, Levy HR. On the specificity of steroid interaction with mammary gland glucose-6-phosphate dehydrogenase. Biochemistry. 1970; 9:2233-43.

26. Jordan P, Carmo-Fonseca M. Molecular mechanisms involved in cisplatin cytotoxicity. Cellular and Molecular Life Sciences. 2000; 57:1229-35.

27. Arnesano F, Natile G. "Platinum on the road": interactions of antitumoral cisplatin with proteins. Pure and Applied Chemistry. 2008; 80:2715-2725.

28. Liu H, Liu Y, Zhang JT. A new mechanism of drug resistance in breast cancer cells: fatty acid synthase overexpression-mediated palmitate overproduction. Molecular Cancer Therapeutics. 2008; 7:263-270.

29. Sala G, Trombin F, Beretta S, Tremolizzo L, Presutto P, Montopoli M, Fantin M, Martinuzzi A, Carelli V, Ferrarese C. Antioxidants partially restore glutamate transport defect in Leber hereditary optic neuropathy cybrids. Journal of Neuroscience Research. 2008; 86:3331-7.

30. Kaipparettu BA, Ma Y, Wong LJ. Functional effects of cancer mitochondria on energy metabolism and tumorigenesis: utility of transmitochondrial cybrids. Annals of the New York Academy of Sciences. 2010; 1201:137-46.

31. Perli E, Giordano C, Tuppen HA, Montopoli M, Montanari A, Orlandi M, Pisano A, Catanzaro D, Caparrotta L, Musumeci B, Autore C, Morea V, Di Micco P, et al. Isoleucyl-tRNAsynthetase levels modulate the penetrance of a homoplasmic m.4277T $>C$ mitochondrial tRNA(Ile) mutation causing hypertrophic cardiomyopathy. Human Molecular Genetics. 2012; 21:85-100.

32. Strohecker AM, Guo JY, Karsli-Uzunbas G, Price SM, Chen GJ, Mathew R, McMahon M, White E. Autophagy sustains mitochondrial glutamine metabolism and growth of BrafV600E-driven lung tumors. Cancer Discovery. 2013; $3: 1272-85$.

33. Lustberg MB, Edelman MJ. Optimal duration of chemotherapy in advanced non-small cell lung cancer. Current Treatment Options in Oncology. 2007; 8:38-46.
34. Tai DJ, Jin WS, Wu CS, Si HW, Cao XD, Guo AJ, Chang JC. Changes in intracellular redox status influence multidrug resistance in gastric adenocarcinoma cells. Experimental and Therapeutic Medicine. 2012; 4:291-296.

35. Blagosklonny MV. Oncogenic resistance to growth-limiting conditions. Nature Reviews Cancer. 2002; 2:221-5.

36. Blagosklonny MV. NCI's provocative questions on cancer: some answers to ignite discussion. Oncotarget. 2011; 2:1352-67.

37. Ramos-Montoya A, Lee WN, Bassilian S, Lim S, Trebukhina RV, Kazhyna MV, Ciudad CJ, Noé V, Centelles JJ, Cascante M. Pentose phosphate cycle oxidative and nonoxidative balance: A new vulnerable target for overcoming drug resistance in cancer. International Journal of Cancer. 2006; 119:2733-41.

38. King MP, Attardi G. Human cells lacking mtDNA: repopulation with exogenous mitochondria by complementation. Science. $1989 ; 246: 500-3$.

39. Giordano C, Montopoli M, Perli E, Orlandi M, Fantin M, Ross-Cisneros FN, Caparrotta L, Martinuzzi A, Ragazzi E, Ghelli A, Sadun AA, D'Amati G, Carelli V. Oestrogens ameliorate mitochondrial dysfunction in Leber's hereditary optic neuropathy. Brain. 2011; 134:220-34.

40. Tuppen HA, Fehmi J, Czermin B, Goffrini P, Meloni F, Ferrero I, He L, Blakely EL, McFarland R, Horvath R, Turnbull DM, Taylor RW. Long-term survival of neonatal mitochondrial complex III deficiency associated with a novel BCS1L gene mutation. Molecular Genetics and Metabolism. 2010; 100:345-8.

41. Mussini C, Pinti M, Bugarini R, Borghi V, Nasi M, Nemes E, Troiano L, Guaraldi G, Bedini A, Sabin C, Esposito R, Cossarizza A. Effect of CD4-monitored treatment interruption on mitochondrial DNA content in HIV-infected patients: a prospective study. AIDS. 2005; 19:1627-33.

42. Chomczynski P, Sacchi N. Single-step method of RNA isolation by acid guanidiniumthiocyanate-phenol-chloroform extraction. Analytical Biochemistry. 1987; 162:156-9.

43. Yizhak K, Gaude E, Le Dévédec S, Waldman YY, Stein GY, van de Water B, Frezza C, Ruppin E. Phenotype-based cellspecific metabolic modeling reveals metabolic liabilities of cancer. Elife. 2014; 3. doi: 10.7554/eLife.03641.

44. Floreani M, Petrone M, Debetto P, Palatini P. A comparison between different methods for the determination of reduced and oxidized glutathione in mammalian tissues. Free Radical Research. 1997; 26:449-55.

45. Loewe $\mathrm{S}$. The problem of synergism and antagonism of combined drugs. Arzneimittelforschung. 1953; 3:285-90.

46. Tallarida RJ. An overview of drug combination analysis with isobolograms. Journal of Pharmacology and Experimental Therapeutics. 2006; 319:1-7. 